\title{
Knowledge levels related to allergen specific immunotherapy and perspectives of parents whose children were diagnosed with asthma and/or allergic rhinitis in Turkey
}

\author{
Sakine Işık ${ }^{1}$, Şule Çağlayan-Sözmen ${ }^{1}$, Suna Asilsoy ${ }^{1}$, Serdar Kamer Kılıçarslan², \\ Özden Anal ${ }^{1}$, Özkan Karaman ${ }^{1}$, Nevin Uzuner ${ }^{1}$ \\ Departments of ${ }^{1}$ Pediatric Allergy and Immunology and ${ }^{2}$ Pediatrics, Dokuz Eylul University Faculty of Medicine, Izmir, \\ Turkey. E-mail: drsakinekar83@hotmail.com \\ Received: 8th May 2017, Revised: 17th July 2017, Accepted: 30th July 2017
}

SUMMARY: Işı1k S, Çağlayan-Sözmen Ş, Asilsoy S, Kılıçarslan SK, Anal Ö, Karaman Ö, Uzuner N. Knowledge levels related to allergen specific immunotherapy and perspectives of parents whose children were diagnosed with asthma and/or allergic rhinitis in Turkey. Turk J Pediatr 2018; 60: 50-55.

In the present study, we aimed to evaluate the knowledge levels and perspectives about allergen specific immunotherapy (ASI) of parents whose children were diagnosed with asthma and/or allergic rhinitis with positive skin prick test. The study was conducted between September 2014 and January 2015. Surveys that were filled by 198 parents were analyzed. One hundred-ninety-eight parents were included in the study; $42.9 \%$ of the parents had knowledge about ASI. Parents obtained information about the ASI from respectively pediatric allergy specialists $(25.5 \%)$, relatives and friends $(17.8 \%)$, media $(12.9 \%)$, and pediatrician $(8.2 \%)$. There is a strong association between educational level of the mother, atopy background of the family, the monthly per capita income, and having knowledge about the ASI. Multivariate regression analysis revealed that individuals with a monthly income higher than 2,000 TL were more likely to be aware of the ASI application (OR: 4.35, 95\% CI: 1.13 $16.71 ; p<0.05)$. Eighty-nine percent of the parents stated that they would prefer the sublingual ASI instead of subcutaneous ASI because it is easy to use and its severe side effects risk is low. The awareness of the ASI is at high rates in our patient population.

Key words: allergen specific immunotherapy, allergic rhinitis, asthma, children, knowledge level, perspective.

Allergic airway disease is a growing problem throughout the world. ${ }^{1}$ There is a dramatic increase in the prevalence of allergic diseases in the last four decades. Respiratory allergies have become the most common chronic disease among adolescent and young adults. ${ }^{2,3}$ There are updated treatment approaches for asthma and allergic rhinitis such as training of the patient, protecting from allergens, pharmacotherapy, and allergen specific immunotherapy (ASI) ${ }^{4,5}$

ASI has been applied approximately for the last 100 years and it is the unique treatment method which can change the natural course of the disease in case of respiratory allergies. It has been shown that the immunological mechanism of action increases the immune tolerance. ${ }^{6}$

ASI is mainly prescribed and managed by allergists. But, the presence of allergist seems to be largely insufficient in this specific field of immunotherapy and knowledge about ASI is low overall and varies widely by country: in Europe, $30 \%$ had never heard of ASI. ${ }^{7}$

The aim of this study is to determine knowledge levels related to allergen specific immunotherapy (ASI) and perspectives of parents whose children were diagnosed with asthma and/or allergic rhinitis with positive skin prick test in our pediatric allergy and immunology outpatient clinic. 


\section{Material and Methods}

The study was conducted between September 2014 and December 2015 in pediatric allergy and immunology outpatient clinic. Before conducting the study, the permission was obtained from the Non-invasive Clinical Ethics Committee (2014/09-21). The survey was composed of 7 questions related to the demographical and socio-cultural characteristics of parents, 8 questions related to the knowledge levels of parents about ASI, and 2 questions related to the views of parents about ASI. We included the parents of children who have been followed up at least for the last three years in the pediatric allergy and immunology outpatient clinic with asthma and/or allergic rhinitis and who have skin test positivity for at least one of the inhalant allergens. Asthma and allergic rhinitis were diagnosed in line with the international guidelines. ${ }^{5,8}$ Consents of families whose children met the criteria were obtained and the surveys were applied to them. The data of the study were recorded in the SPSS for Windows V.16 (SPSS, Inc., Chicago, Illinois) program. Frequency (\%), mean and standard deviation $( \pm S D)$ or median (IQR: interquartile range) were used for the descriptive statistical analyses. Chi-square analysis was used to compare the groups. A $\mathrm{p}$ value $<0.05$ was accepted as statistically significant. Variables with a $\mathrm{p}$ value $<0.20$ according to univariate analysis were further evaluated with multivariate logistic regression analysis with backward elimination method and Odds ratios were presented with their 95\% confidence intervals.

\section{Results}

Totally, 198 parents were included in the study. The median age of patients was 9.5 years (IQR

Table I. Demographic Characteristics of the Patients and Parents $(\mathrm{N}=198)$.

\begin{tabular}{lr}
\hline Characteristics & $\mathrm{N}(\%)$ \\
\hline Disease & \\
Asthma & $84(42.6)$ \\
Allergic rhinitis & $35(17.8)$ \\
Asthma and allergic rhinitis & $79(39.6)$ \\
Disease duration (years) & \\
$0-1$ & $54(27.6)$ \\
$1-3$ & $62(31.3)$ \\
$3-5$ & $38(19)$ \\
$5-10$ & $44(22.1)$ \\
Family history for atopy & \\
Yes & $108(55)$ \\
First degree relatives & $44(22)$ \\
Other relatives & $46(23)$ \\
No & $37.5 \pm 5.9$ \\
Age of the mother (years) & $41.6 \pm 6.8$ \\
Age of the father (years) & \\
Educational level & $3(1.3)$ \\
Mother & $53(27)$ \\
Illiterate & $21(10.4)$ \\
Primary school & $65(33)$ \\
Secondary school & $56(28.3)$ \\
High school & \\
University & $2(1)$ \\
Father & $75(38.1)$ \\
Illiterate & $19(9.5)$ \\
Primary school & $54(27.2)$ \\
Secondary school & $48(24.2)$ \\
High school & $3462 \pm 1635$ \\
University & \\
Monthly income (Turkish Liras) & \\
\hline ASt Aleg secific ing & \\
\hline
\end{tabular}

ASI: Allergen specific immunotherapy 
6.9-12.9). The median age of mothers was 37 years (IQR 33-42) and the median age of fathers was 41 years (IQR 36.75-45); $42.6 \%$ of the patients were diagnosed only with asthma $(n=84), 17.8 \%$ of them were diagnosed only with allergic rhinitis $(n=35)$, and $39.6 \%$ of them were diagnosed with both asthma and allergic rhinitis $(n=79)$ (Table I).

The frequency of parents stating that they were aware of the ASI application for allergic disease treatment was $42.6 \%$. Parents reached this information respectively from pediatric allergy specialists $(25.5 \%)$, relatives and friends $(17.8 \%)$, media (television, internet, newspapers, etc), and pediatricians (8.2\%).

Twenty-three percent of the parents did not have an atopy background whereas at least one of the $55 \%$ of the family members (mothers, fathers and/or siblings) had an atopy history. Furthermore, $22 \%$ of the other relatives also had a history of an atopy. Individuals with an atopy background in the family had higher

Table II. Parents Knowledge and Perception About ASI.

\begin{tabular}{|c|c|c|}
\hline Item & $\mathrm{N}$ & $(\%)$ \\
\hline \multicolumn{3}{|l|}{$\begin{array}{l}\text { Did you previously know that } \\
\text { allergen spesific immunotherapy (ASI) } \\
\text { was used for allergic disease? }\end{array}$} \\
\hline Yes & 84 & 42.6 \\
\hline No & 118 & 57.4 \\
\hline \multicolumn{3}{|c|}{$\begin{array}{l}\text { Do you think the ASI leads to a complete recovery } \\
\text { of allergic diseases? }\end{array}$} \\
\hline Yes & 16 & 8 \\
\hline No & 14 & 7 \\
\hline No idea & 168 & 85 \\
\hline \multicolumn{3}{|c|}{$\begin{array}{l}\text { Does the ASI decrease the drug use frequency } \\
\text { in asthma and/or allergic rhinitis treatment? }\end{array}$} \\
\hline Yes & 69 & 34.9 \\
\hline No & 27 & 13.6 \\
\hline No idea & 102 & 51.5 \\
\hline \multicolumn{3}{|c|}{$\begin{array}{l}\text { Does the ASI prevent the development of asthma } \\
\text { in allergic rhinitis patients? }\end{array}$} \\
\hline Yes & 21 & 10.6 \\
\hline No & 4 & 2 \\
\hline No idea & 173 & 87.4 \\
\hline \multicolumn{3}{|c|}{$\begin{array}{l}\text { Can the ASI be applied both by injection and } \\
\text { via oral route? }\end{array}$} \\
\hline Yes & 21 & 10.6 \\
\hline No, (ASI can applied only by injection & 30 & 15.2 \\
\hline No idea & 147 & 74.2 \\
\hline \multicolumn{3}{|c|}{$\begin{array}{l}\text { Do you think there can be severe and fatal reactions } \\
\text { during the ASI application? }\end{array}$} \\
\hline Yes & 19 & 9.5 \\
\hline No & 3 & 1,5 \\
\hline No idea & 176 & 89 \\
\hline \multicolumn{3}{|c|}{ Do you think the ASI will lead to become a habit? } \\
\hline Yes & - & - \\
\hline No & 45 & 22.7 \\
\hline No idea & 153 & 77.3 \\
\hline \multicolumn{3}{|c|}{$\begin{array}{l}\text { Do you think that the sublingual ASI } \\
\text { is safer compared to the subcutaneous ASI? }\end{array}$} \\
\hline Yes & 9 & 4.5 \\
\hline No & 2 & 1 \\
\hline No idea & 187 & 94.5 \\
\hline
\end{tabular}

ASI: Allergen specific immunotherapy 
awareness rates (49.2\%) for ASI application in the allergic disease treatment compared to ones without a family history $(29.5 \%$; $\mathrm{p}=0.01)$. The mean monthly income of parents was 3,462 $\pm 1,635$ Turkish Liras (TL). Individuals who had a monthly income more than 1,500 TL were significantly more aware for ASI application (66.7\%) compared to individuals who have a level of income less than 1,500 TL (39.0\%; $p=0.07) .27 .6 \%, 31.3 \%, 19 \%$, and $22.1 \%$ of patients were followed up respectively for the last 0-1 year, 1-3 year, 3-5 years, and 5-10 years with the diagnosis of asthma and/or allergic rhinitis. Individuals with a duration of diagnosis more than 5 years were more likely to be aware of the ASI application (57.7\%), compared to patients who were diagnosed preceding 5 years $(43.6 \%)$, however this relationship was not significant $(p=0.198)$

Mothers with an education level equal or more than high school had higher awareness for ASI application (52.5\%) compared to those with lower education level (31.5\%; $\mathrm{p}=0.005)$. Fathers with an education level equal or more than high school had higher awareness for ASI application (49.2\%) compared to those

Multivariate regression analysis revealed that individuals with a monthly income higher than 2,000 TL were more likely to be aware of the ASI application (OR: 4.35, 95\% CI: $1.13-16.71 ; \mathrm{p}<0.05)$ compared to individuals who have an income less than 2,000 TL. All other independent variables were eliminated from the model.

Parents knowledge, perception and attitudes are shown in Table II and III, respectively.

\section{Discussion}

Allergic airway diseases such as allergic asthma and allergic rhinitis are growing problems throughout the world. ${ }^{1}$ Both of these diseases lead to deterioration of sleeping habits and decrease the quality of work and school life. ${ }^{9,10}$ Treatment approaches for asthma and allergic rhinitis include: training of the patient, protecting from allergens, pharmacotherapy, and allergen specific immunotherapy (ASI). ${ }^{5}$ Even though it is possible to protect the patient from allergens, it is hard to control the symptoms in allergic respiratory diseases in daily life by only protecting the patient from allergens. There are cheap and safe drugs in the treatment of allergic symptoms. However, $57 \%$ of the patients can experience side effects of these drugs and sufficient symptom control may not be ensured.11,12 Furthermore, pharmacotherapy may not have an effect on the course of the disease and it is required to have the drugs as long as the patients have the symptoms throughout their life.

ASI was first applied by Leonard Noon 104 years ago by administering pollen extracts to the patient subcutaneously. It is a unique and potential therapy for allergic diseases by changing the natural course of the disease, preventing the asthma and new allergen sensitivity, and increasing the allergen specific immune tolerance. ${ }^{13}$ ASI has been applied for respiratory diseases such as allergic asthma and allergic rhinitis, venom allergies, and recently for food allergy and atopic dermatitis.

ASI was primarily applied subcutaneously and its use was limited because of its fatal side effects in 1980s. Researchers have tried to find safer routes of drug administration. ${ }^{14}$ Sublingual ASI has been increasingly applied in various European countries in the last 25 years because of low rates of severe side effects and ease of its use. ${ }^{15}$ Some local and systemic side effects of ASI have been reported. Local reactions are observed both subcutaneous ASI (erythema, itching and swelling at the injection site) and sublingual ASI (oropharyngeal itching, edema). These reactions can be observed in the $82 \%$ of the patients who receive subcutaneous ASI and $75 \%$ of the patients who receive sublingual ASI. ${ }^{16,17}$ The side effect risk is prominently lower in sublingual ASI when compared to subcutaneous ASI. ${ }^{17}$

The effectiveness of the ASI has been shown in important clinical studies and meta-analyses. However, it has a limited use and it is estimated that its frequency of use is less than $10 \%$ in allergic rhinitis and asthma patients throughout the world ${ }^{13}$. There are some reasons why ASI is rarely used: 1) there is a lack of consensus about its efficiency and safety, 2) there is a the lack of data about its cost effectiveness, 3 ) it has the long duration of treatment and 4) there is a lack of awareness of the ASI treatment in the general population and among physicians who did not receive allergy and immunology education. ${ }^{18}$ In general, ASI is mainly prescribed and managed by allergist. 
Table III. Attitudes of Parents for ASI.

\section{Item}

$\mathrm{N}$

1- What would you do when the physician decides to use ASI treatment because other medications are not sufficiently beneficial for your child?

I trust the physician who follows up my child, thus I let the doctor do what he/she decides."

"I search for the method through internet

and then I decide it"

"I would ask to another physician and then I decide it"

2- Which route do you prefer for ASI for your child? Subcutaneous

Sublingual

In some European countries, allergology is not recognized or has been discontinued as a separate medical specialty, and allergic patients are often treated by other specialists. Low usage and knowledge in some countries could potentially be attributed to limited patient access to the specialist physicians likely to prescribe (and provide information on) this treatment. In ALL (Allergy Living and Learning) study, when patients were asked about their knowledge of ASI, $30 \%$ had never heard of it, less than half (47\%) knew something or a little about it, and only $23 \%$ knew it well or really well. These values varied widely across Europe, with $52 \%$ of patients in Sweden knowing nothing about ASI as compared with $10 \%$ of patients in Italy. Only 7\% of patients in the UK knew this treatment well or really well, as compared with $44 \%$ in Germany. However, the general level of interest in ASI was more consistent between countries, with $30 \%$ of patients stating that they were interested in ASI. ${ }^{7}$

Our present study is the first study in Turkey which evaluates the knowledge levels related to allergen specific immunotherapy (ASI) and perspectives of parents whose children were diagnosed with asthma and/or allergic rhinitis. Our study was conducted in Izmir which is one of the most developed cities in Turkey and which is one of the cities in which the literacy rate is quite high. According to our findings, the awareness of ASI is quite high in our patient population (42.6\%).

Allergic diseases and their treatments have recently been mentioned via information programs (such as public spots and television programs related to medical issues, etc.) and articles in media such as television, internet, and newspaper. This leads to raised awareness of individuals about ASI. There is no such study in which it is shown how parents of pediatric patients with allergic rhinitis and asthma can reach the information about ASI and the opinions of these families about ASI have also not been given in any of the studies. In our country, ASI was managed by pediatric allergy specialist in pediatric patients with allergic rhinitis and/or asthma. In this study, it has been concluded that most of the parents reached the information about ASI via pediatric allergy specialist $(25.5 \%)$. It could be because it is easy to directly reach pediatric allergy specialists in Izmir, Turkey.

There is a significant relationship between having knowledge about the ASI in the treatment of allergic diseases and the presence of atopy in the family, the education level of mothers, and monthly per capita income in the family. The awareness of ASI application that is used in allergic diseases is high in families when there is an atopy background in at least one individual of the family members (motherfather or siblings), when the education level of the mother is high, and when the monthly per capita income is high. In our study, the awareness of ASI that is used in allergic diseases is high and the information about ASI is less, as estimated. It was detected that only $10.6 \%$ of the families have proper knowledge about the subcutaneous and sublingual application of the ASI, $4.5 \%$ of them were aware of that sublingual ASI is safer, $9.5 \%$ of them knew 
that there can be fatal side effects during the ASI treatment, $10.6 \%$ of them were aware of that ASI prevents the asthma in allergic rhinitis patients, and $34.9 \%$ of them knew that ASI decreases the drug use requirements.

In our study, we firstly evaluated the parents' opinions related to subcutaneous and sublingual ASI. After informing parents about subcutaneous and sublingual ASI; $88.7 \%$ of them preferred sublingual ASI because it is easy to apply and its severe side effect incidence is low.

Consequently, the majority of our patient population has the knowledge of ASI that is applied in allergic diseases and they reached this information mostly via pediatric allergy specialist. The frequency of ASI use in allergic diseases is low both in the world as well as in Turkey. It is thought that allergists and media outlets have important roles in explaining the benefits and efficiency of ASI application which can change the course of the disease. Our study is important because it mentions the views of parents whose children were diagnosed with allergic rhinitis and/or asthma with positive skin prick test. Furthermore, how these parents reached the information about ASI and their opinions related to subcutaneous and sublingual ASI are also firstly evaluated in our study.

\section{REFERENCES}

1. Pawankar R, Holgate ST, Canonica GW, Lockey RF. White Book on Allergy. World Allergy Organization, 2011.

2. Ring J, Akdis $\mathrm{C}$, Behrendt $\mathrm{H}$, et al. Davos declaration: Allergy as a global problem. Allergy 2012; 67: 141-143.

3. Calderon MA, Demoly P, Gerth van Wijk R, et al. EAACI: A European Declaration on Immunotherapy. Designing the future of allergen specific immunotherapy. Clin Transl Allergy 2012; 2: 20.

4. Papadopoulos NG, Agache I, Bavbek S, et al. Research needs in allergy: An EAACI position paper, in collaboration with EFA. Clin Transl Allergy 2012; 2: 21.
5. Bousquet J, Khaltaev N, Cruz AA, et al. Allergic rhinitis and its impact on asthma (ARIA) 2008 update (in collaboration with the World Health Organization, GA(2)LEN and AllerGen). Allergy 2008; 6: 8-160.

6. Abramson MJ, Puy RM, Weiner JM. Allergen immunotherapy for asthma. Cochrane Database Syst Rev 2003; 4: CD001186.

7. Chivato T, Valovirta E, Dahl R, et al. Allergy, living and learning: Diagnosis and treatment of allergic respiratory diseases in Europe. J Investig Allergol Clin Immunol 2012; 22: 168-179.

8. Global Initiative for Asthma (GINA). Available at: http:/www.ginaasthma.org (Accessed 15 ${ }^{\text {th }}$ April 2017).

9. Le'ger D, Annesi-Maesano I, Carat F, et al. Allergic rhinitis and its consequences on quality of sleep: An unexplored area. Arch Intern Med 2006; 166: 17441748.

10. Hellgren J, Cervin A, Nordling S, et al. Allergic rhinitis and the common cold - high cost to society. Allergy 2010; 65: 776-783.

11. Ibero M, Justicia JL, Alvaro M, et al. Diagnosis and treatment of allergic rhinitis in children: Results of the PETRA study. Allergol Immunopathol 2012; 40: 138-143.

12. White P, Smith $\mathrm{H}$, Baker N, et al. Symptom control in patients with hay fever in UK general practice: How well are we doing and is there a need for allergen immunotherapy? Clin Exp Allergy 1998; 28: 266-270.

13. Jutel $\mathrm{M}$, Agache I, Bonini $\mathrm{S}$, et al. International consensus on allergy immunotherapy. J Allergy Clin Immunol 2015; 136: 556-568.

14. CMS update: Desensitizing vaccines. BMJ 1986; 293 948.

15. Bauer CS, Rank MA. Comparative efficacy and safety of subcutaneous versus sublingual immunotherapy. J Allergy Clin Immunol 2014; 134: 765

16. Cox L, Nelson H, Lockey R, et al. Allergen immunotherapy: a practice parameter third update. J Allergy Clin Immunol 2011; 127: 1-55.

17. Cox LS, Linnemann DL, Nolte H, Weldon D, Finegold I, Nelson HS. Sublingual immunotherapy: A comprehensive review. J Allergy Clin Immunol 2006; 117: 1021-1035.

18. Calderon MA, Cardona V, Demoly P. EAACI 100 Years of Immunotherapy Experts Panel. One hundred years of allergen immunotherapy European Academy of Allergy and Clinical Immunology celebration: Review of unanswered questions. Allergy 2012; 67: 462-476. 